\title{
Half-sandwich Mo(III) complexes with asymmetric diazadiene ligands
}

François Stoffelbach, ${ }^{a}$ Philippe Richard, ${ }^{a}$ Rinaldo Poli*b ${ }^{\text {, Titus Jenny }{ }^{\mathrm{c}} \text { and Corinne Savary }}{ }^{\mathrm{c}}$

${ }^{a}$ Laboratoire de Synthèse et d'Electrosynthèse Organométalliques, UMR-CNRS-5188, Faculté des Sciences "Mirande", Université de Bourgogne, 9 Avenue Alain Savary, 21078 Dijon CEDEX, France

${ }^{\mathrm{b}}$ Laboratoire de Chimie de Coordination, UPR CNRS 8241, lié par convention à l'Université Paul Sabatier et à l'Institut National Polytechnique de Toulouse, 205 Route de Narbonne, 31077 Toulouse Cedex, France.

${ }^{\mathrm{c}}$ Département de Chimie, Université de Fribourg, Route du Musée 9, CH-1700 Fribourg, Switzerland

Proofs to:

Rinaldo Poli

Tel: $+33-561333195$

Fax: $+33-561553003$

E-mail: poli@lcc-toulouse.fr 


\section{Summary}

The asymmetric 1,4-diazadiene ligands $\mathrm{R} * \mathrm{~N}=\mathrm{CHCH}=\mathrm{NR} *\left[\mathrm{R}^{*}=(S)-\mathrm{CH}\left(\mathrm{CH}_{3}\right) \mathrm{Ph}\right], \mathbf{R} * 2 \mathbf{d a d}$, and 2,2'-bis(4-ethyloxazoline), as-ox, have been used to generate half-sandwich $\mathrm{Mo}^{\mathrm{III}}$ derivatives by addition to $\mathrm{Cp}_{2} \mathrm{Mo}_{2} \mathrm{Cl}_{4}$. Ligand $\mathbf{R}_{2}$ dad affords a mononuclear, paramagnetic 17-electron product, $\mathrm{CpMoCl}_{2}\left(\mathbf{R} *_{2} \mathbf{d a d}\right)$, whereas as-ox leads to the isolation of a dinuclear compound where only one molecule of ligand has been added per two Mo atoms, $\mathrm{Cp}_{2} \mathrm{Mo}_{2} \mathrm{Cl}_{4}(\boldsymbol{a s}-\mathbf{o x})$. In the presence of free as-ox, this compound coexists with the paramagnetic mononuclear complex in solution. Both products are capable to control the radical polymerization of styrene under typical atom transfer radical polymerization (ATRP) conditions. However, the tacticity of the resulting polystyrene does not differ from that given by conventional free radical polymerization.

\section{Keywords}

Molybdenum, Atom Transfer Radical Polymerization, Polystyrene, Half-sandwich Complexes, Diazadiene 


\section{Introduction}

In recent years, a number of coordination and organometallic compounds based on different transition metals have been shown to be capable of controlling the radical polymerization of activated olefins through a process that has been termed Atom Transfer Radical Polymerization (ATRP), see Scheme $1 .^{[1,2]}$ The active radical concentration is maintained at very low levels though a reversible equilibrium with a dormant species, thereby reducing the incidence of bimolecular terminations.

\section{$<$ Scheme 1>}

Systems based on a variety of transition metals, including $\mathrm{Ti}^{\mathrm{III}},{ }^{[3]} \mathrm{Mo}^{\mathrm{III}},{ }^{[4,5]} \mathrm{Re}^{\mathrm{V}}$, ${ }^{6]}$ $\mathrm{Fe}^{\mathrm{II}},{ }^{[7,8]} \mathrm{Ru}^{\mathrm{II}},{ }^{[9]} \mathrm{Ni}^{\mathrm{II}},{ }^{[10]} \mathrm{Ni}^{0},{ }^{[11]}$ and $\mathrm{Cu}^{\mathrm{I}}{ }^{[12]}$ have been shown effective. Although no system currently appears to parallel the activities and practical advantages of certain $\mathrm{Cu}^{\mathrm{I}}$ complexes, the investigation of other metal systems is useful in order to shine light on the mechanistic details of the process.

In spite of many observations in agreement with the mechanism shown in Scheme 1, certain experimental facts have suggested the possibility of a more complex mechanism. For instance, it has been shown that a large amount of phenol does not inhibit the ATRP of MMA catalyzed by copper(I) bromide, ${ }^{[13]}$ and that the medium polarity could have an important effect on the rate of polymerization. ${ }^{[14,15]}$ Recently, a different ${ }^{13} \mathrm{C}$ isotope effect has been reported for the $\mathrm{Cu}^{\mathrm{I}}$-catalyzed ATRP of methyl methacrylate relative to the free radical polymerization process, suggesting a difference in the nature of the transition state for the propagation step. ${ }^{[16]}$ Although these data have later been fully rationalized without the need to modify the mechanism, ${ }^{[17]}$ further work has shown that, under certain circumstances and for 
certain catalysts, the monomer can coordinate to the metal center. ${ }^{[18]}$ This feature seems to open the way to the growth of stereoregular polymers, provided the metal is contained within an asymmetric coordination environment, the olefin coordination step is enantioselective, and the coordinated monomer is more susceptible than the free monomer to radical addition. The control of stereochemistry in radical polymerization attracts considerable interest. Moderate success in this goal has been achieved by using a grafted chiral auxiliary on the monomer ${ }^{[19]}$ and by using a Lewis acid additive which is capable to reversibly interact with the monomer. ${ }^{[20,21]}$

Since we have recently developed a series of active ATRP catalysts based on halfsandwich molybdenum complexes of 1,4-diazadiene ligands, ${ }^{[5,22,23]}$ and since asymmetric versions of such ligands are well established, ${ }^{[24]}$ we have decided to prepare the related Mo complexes and to test them in controlled radical polymerization.

\section{Experimental Section}

General procedures. (a) Materials. All manipulations were carried out under an atmosphere of dry and oxygen-free argon with standard Schlenk techniques. Toluene, THF and pentane were purified by reflux over sodium benzophenone ketyl and distilled under argon prior to use. $\mathrm{CH}_{2} \mathrm{Cl}_{2}$ was dehydrated with $\mathrm{P}_{4} \mathrm{O}_{10}$ and distilled under argon. Styrene was washed with an aqueous $\mathrm{NaOH}$ solution (10\%), followed by water, then dried over $\mathrm{MgSO}_{4}$ and finally distilled at $25^{\circ} \mathrm{C}$ under reduced pressure. (1-Bromoethyl)benzene (BEB) and $\mathrm{Al}(\mathrm{O}-i-\mathrm{Pr})_{3}$ (Aldrich) wera used as received. $\left[\mathrm{CpMo}(\mu-\mathrm{Cl})_{2}\right]_{2}{ }^{[25]}$ and $\mathrm{CH}_{3} \mathrm{CH}(\mathrm{I}) \mathrm{COOEt}$ $(\text { IEA })^{[26]}$ were prepared as described in the literature. Glyoxal $(40 \%$ in water) and $(S)$ $\mathrm{H}_{2} \mathrm{NCH}\left(\mathrm{CH}_{3}\right) \mathrm{Ph}$ (Aldrich) were used as received. The bisoxazoline ligands were prepared by 
adapting and optimizing a known procedure ${ }^{[27]}$ involving commercial chiral aminoalcohols (Fluka).

(b) Physical measurements. Molecular weights and molecular weight distributions were measured with a Gynkoteck P580 size exclusion chromatographer equipped with a refractometer and 2 B Jordi DVB columns (range 1000-1000000) using THF as eluent (1 $1 \mathrm{~mL} / \mathrm{min})$. The instrument was calibrated by using polystyrene standards. EPR measurements were carried out at the X-band microwave frequency on a Bruker ESP300 spectrometer. The spectrometer frequency was calibrated with diphenylpicrylhydrazyl (DPPH, $g=2.0037$ ). Cyclic voltammograms were recorded with an EG\&G 362 potentiostat connected to a Macintosh computer through MacLab hardware/sofware. The electrochemical cell was fitted with an $\mathrm{Ag}-\mathrm{AgCl}$ reference electrode, a platinum disk working electrode and a platinum wire counter-electrode. $\left[\mathrm{Bu}_{4} \mathrm{~N}\right] \mathrm{PF}_{6}($ ca. $0.1 \mathrm{M})$ was used as supporting electrolyte in THF. All potentials are reported relative to the ferrocene standard, which was added to each solution and measured at the end of the experiments. The elemental analyses were carried out by the analytical service of the LSEO laboratory with a Fisons EA 1108 apparatus. NMR spectra were recorded on a Brucker DRX 500 spectrometer. The peaks positions are reported with positive shifts in ppm downfield of TMS, as calculated from residual solvent peaks.

Preparation of $\mathbf{R}^{*} 2 \mathrm{dad}\left[\mathbf{R}^{*}=(S)-\mathbf{C H}\left(\mathbf{C H}_{3}\right) \mathbf{P h}\right]$. Glyoxal $(0.9 \mathrm{~g}, 15.5 \mathrm{mmol})$ and $(S)$ $\mathrm{PhCH}\left(\mathrm{CH}_{3}\right) \mathrm{NH}_{2}(4 \mathrm{~mL}, 31.0 \mathrm{mmol})$ were mixed in $10 \mathrm{~mL}$ of $\mathrm{MeOH}$ at room temperature. The mixture was then stirred for $3 \mathrm{~h}$ at $70^{\circ} \mathrm{C}$. The ligand was extracted with $60 \mathrm{~mL}$ of heptane. An oil was obtained by cooling the solution to $-80^{\circ} \mathrm{C}$. After decanting off the mother liquor, the oil was distilled under reduced pressure. ${ }^{1} \mathrm{H}$ NMR $\left(\mathrm{CDCl}_{3}, 25^{\circ} \mathrm{C}\right): \delta 1.60(\mathrm{~d}, J=$ $\left.6.7 \mathrm{~Hz}, \mathrm{CH}_{3}\right), \delta 4.52(\mathrm{q}, J=6.7 \mathrm{~Hz}, \mathrm{CH}), \delta 7.20-7.40(\mathrm{~m}, \mathrm{Ph}), \delta 8.07(\mathrm{~s}, \mathrm{CH}=\mathrm{N})$.

Synthesis of complex $\mathbf{C p M o C l} \mathbf{l}_{2}\left[\mathbf{R} *_{2} \mathbf{d a d}\right] .\left[\mathrm{CpMo}(\mu-\mathrm{Cl})_{2}\right]_{2}(0.360 \mathrm{~g}, 0.78 \mathrm{mmol})$ and $\mathbf{R} *{ }_{2}$ dad $(0.183 \mathrm{~g}, 1.78 \mathrm{mmol})$ were suspended in $15 \mathrm{~mL}$ of toluene at room temperature. The 
mixture was then stirred for $24 \mathrm{~h}$ at $70^{\circ} \mathrm{C}$. The solution was filtered through Celite to remove a small amount of residual solid and concentrated under reduced pressure to ca. $6 \mathrm{~mL}$. Addition of $10 \mathrm{~mL}$ of pentane gave the product as a red brown microcrystalline solid, which was washed with pentane ( $3 \times 5 \mathrm{~mL})$ and dried in vacuo. Yield: $0.502 \mathrm{~g}(65 \%)$. Anal. Calc. for $\mathrm{C}_{23} \mathrm{H}_{25} \mathrm{Cl}_{2} \mathrm{MoN}_{2}$ : C 55.66, H 5.08, N $5.64 \%$. Found: C 55.05, H 5.53, N $5.16 \%$. EPR $\left(\mathrm{CH}_{2} \mathrm{Cl}_{2}\right): \mathrm{g}=1.976\left(\mathrm{a}_{\mathrm{Mo}}=45.2 \mathrm{G}\right)$. Cyclic voltammetry $(\mathrm{THF}):$ reversible oxidation with $\mathrm{E}_{1 / 2}$ $=+0.05 \mathrm{~V}\left(\Delta \mathrm{E}_{\mathrm{p}}=81 \mathrm{mV}\right)$ and reversible reduction at $\mathrm{E}_{1 / 2}=-1.04 \mathrm{~V}\left(\Delta \mathrm{E}_{\mathrm{p}}=76 \mathrm{mV}\right)$. The ferrocene peak showed $\Delta \mathrm{E}_{\mathrm{p}}=130 \mathrm{mV}$.

Synthesis of $\mathbf{C p}_{2} \mathrm{Mo}_{2} \mathrm{Cl}_{4}($ as $-\mathrm{ox}) . \quad\left[\mathrm{CpMo}(\mu-\mathrm{Cl})_{2}\right]_{2}(0.557 \mathrm{~g}, 1.20 \mathrm{mmol})$ and as-ox (0.470 g, $2.39 \mathrm{mmol})$ were suspended in $15 \mathrm{~mL}$ of dichloromethane at room temperature. The mixture was then stirred for $4 \mathrm{~h}$ at RT. The blue solution was filtered through Celite to remove a small amount of residual solid and evaporated to dryness under reduced pressure. The dark microcrystalline solid was then washed with $7 \mathrm{~mL}$ of pentane and dried in vacuo. Yield: $0.453 \mathrm{~g}(57 \%)$. A recrystallization from $\mathrm{CH}_{2} \mathrm{Cl}_{2} /$ pentane afforded X-ray quality crystals, one of which was used for the X-Ray structural study.

ATRP polymerizations. All ATRP polymerization reactions were performed following the same experimental procedure. The complex was added to a $50 \mathrm{~mL}$ Schlenk tube equipped with a stirring bar. Styrene and (1-bromoethyl)benzene were added to the reaction flask by a syringe. The Schlenk tube was then immersed in an oil bath heated at $90^{\circ} \mathrm{C}$. Aliquots were withdrawn periodically for a reaction monitoring by GPC.

Single crystal X-ray diffraction study. Intensities were collected with a Nonius Kappa CCD diffractometer at $110 \mathrm{~K}$. The structure was solved via a Patterson search program (DIRDIF-99) $^{[28]}$ and refined with full-matrix least squares methods based on $\mathrm{F}^{2}$ (SHELX97) ${ }^{[29]}$ with the aid of the WINGX ${ }^{[30]}$ program. All non-hydrogen atoms were refined with anisotropic thermal parameters. All $\mathrm{H}$ atoms were placed in idealized positions and refined 
using a riding model $[\mathrm{Uiso}(\mathrm{H})=1.2 \mathrm{Ueq}(\mathrm{C}), 1.5$ for methyl groups $]$. The essential crystallographic parameters are listed in Table 1 and selected bond distances and angles are collected in Table 2.

$<$ Table 1 and Table 2 here>

Crystallographic data (excluding structure factors) have been deposited with the Cambridge Crystallographic Data Centre as supplementary publication no. CCDC 271075. Copies of the data can be obtained free of charge on application to the Director, CCDC, 12 Union Road, Cambridge CB2 1EZ, UK (fax: (+44) 1223-336-033; e-mail: deposit@ccdc.cam.ac.uk).

\section{Results and Discussion}

\section{(a) Syntheses and characterization}

The asymmetric $\left(S, S^{\prime}\right)-\mathrm{R}^{*} \mathrm{~N}=\mathrm{CHCH}=\mathrm{NR} *\left[\mathrm{R}^{*}=\mathrm{CH}\left(\mathrm{CH}_{3}\right) \mathrm{Ph}\right]$ ligand $\left(\mathbf{R}_{2}{ }_{2}\right.$ dad $)$ has been prepared by following the same general procedure consisting of the double condensation between glyoxal and the suitable primary amine, ${ }^{[31-34]}$ see Scheme 2. The bisoxazoline ligands were prepared by reaction of the corresponding chiral aminoalcohols with ethyl oxalate to form the bis-amide, followed by substitution of the alcohol functions by chloride and subsequent ring closure to yield the chiral bisoxazolines $(\boldsymbol{a s}-\mathbf{o x}) .^{[27]}$ 
The synthesis of complex $\mathrm{CpMoCl}_{2}\left(\mathbf{R}_{2} \mathbf{d a d}\right)$ has followed the same procedure that were previously reported for the related $\mathrm{CpMoCl}_{2}\left(\mathrm{R}_{2} \mathrm{dad}\right)$ complexes $(\mathrm{R}=i \mathrm{Pr}, \mathrm{Ph}, p$-Tol, $\left.\mathrm{C}_{6} \mathrm{H}_{3 i} \mathrm{Pr}_{2}-2,6\right)$, see Scheme $3 .^{[5]}$ The isolated product has been characterized by EPR spectrometry $\left(\mathrm{g}=1.976\right.$ et $\left.\mathrm{a}_{\mathrm{Mo}}=45.2 \mathrm{G}\right)$ and by electrochemistry (reversible oxidation at $\mathrm{E}_{1 / 2}$ $=+0.05 \mathrm{~V}$ and reversible reduction at $\mathrm{E}_{1 / 2}=-1.04 \mathrm{~V}$, in THF). These properties are essentially identical to those previously reported for complex $\mathrm{CpMoCl}_{2}\left(\mathrm{Pr}_{2} \mathrm{dad}\right)(\mathrm{g}=1.975$; $\left.\mathrm{a}_{\mathrm{Mo}}=42.8 \mathrm{G} ; \mathrm{E}_{1 / 20 x}=0.01 \mathrm{~V} ; \mathrm{E}_{1 / 2 \text { red }}=-1.10 \mathrm{~V}\right)$, to which it is closely related in terms of steric and electronic properties.

$\langle$ Scheme 3>

When an identical procedure was carried out using as-ox, the course of the reaction was visually quite different. Contrary to the reaction with $\mathbf{R} *_{2} \mathbf{d a d}$, which gave a brown solution (like all other previously investigated $\mathrm{R}_{2}$ dad complexes, but also typical of all mononuclear $\mathrm{CpMoCl}_{2} \mathrm{~L}_{2}$ complexes with $\mathrm{L}=$ phosphine or $\mathrm{L}_{2}=$ diphosphine or diene), the reaction with as-ox gave a deep blue solution. The solution EPR spectrum is consistent with the presence of expected mononuclear $\mathrm{CpMoCl}_{2}(\boldsymbol{a s}-\mathbf{o x})$ complex $(\mathrm{g}=2.006$, a $\mathrm{Mo}=32.6 \mathrm{G})$. However, crystallization by slow diffusion of pentane into the reaction mixture in dichloromethane yielded blue crystals, which were revealed to correspond to the dinuclear complex $\mathrm{Cp}_{2} \mathrm{Mo}_{2} \mathrm{Cl}_{4}$ (as-ox) by a single crystal X-ray analysis (see Figure 1 ).

$<$ Figure 1>

The geometry of the compound can be seen as two four-legged piano stools sharing two legs and is precedente for other dinuclear half-sandwich complexes of Mo(III), such as $\left[\mathrm{Cp}_{2} \mathrm{Mo}_{2}(\mu-\mathrm{St} \mathrm{Bu})_{2}(\mathrm{CO})_{4}\right]^{2+} \cdot{ }^{[35]}$ However, this type of structure is unprecedented for neutral 
derivatives of molybdenum(III), i.e. of type $\mathrm{Cp}_{2} \mathrm{Mo}_{2} \mathrm{X}_{4} \mathrm{~L}_{2}$. The addition of neutral ligands to $\mathrm{Cp}_{2} \mathrm{Mo}_{2} \mathrm{Cl}_{4}$ has previously been shown to give either mononuclear $\mathrm{CpMoX}_{2} \mathrm{~L}_{2}$-type compounds directly when the ligand has strong donor properties, or no reaction at all in the case of poor ligands (e.g. amines, ethers). Compound $\mathrm{Cp}_{2} \mathrm{Mo}_{2} \mathrm{Cl}_{4}(\boldsymbol{a s}-\mathbf{o x})$ can be viewed as an intermediate of the process converting the tetrachloro-bridged precursor to the mononuclear bis-ligand adduct. Therefore, the donor properties of the as-ox ligand are in the narrow grey area between those two regions. As the EPR spectrum suggests, the mononuclear compound probably exists in solution, though in equilibrium with the blue dinuclear complex, and it is the latter that crystallized preferentially, see Scheme 4. Because of this equilibrium, no informative NMR spectrum could be recorded for the dinuclear complex. A molecule structurally related to complex $\mathrm{Cp}_{2} \mathrm{Mo}_{2} \mathrm{Cl}_{4}($ as-ox $)$ has been reported for tungsten, $\mathrm{Cp}_{2}{ }_{2} \mathrm{~W}_{2} \mathrm{Cl}_{4}(\mathrm{dmpe})\left(\mathrm{Cp}{ }^{\prime}=\mathrm{C}_{5} \mathrm{H}_{4} \mathrm{Me} ;\right.$ dmpe $\left.=\mathrm{Me}_{2} \mathrm{PCH}_{2} \mathrm{CH}_{2} \mathrm{PMe}_{2}\right) .{ }^{[36]}$ Interestingly, no mononuclear complex of type $\mathrm{CpMX}_{2} \mathrm{~L}_{2}$ has been reported for $\mathrm{W}$ (III) to the best of our knowledge. The reason of the different behaviour between molybdenum and tungsten, for the outcome of the ligand addition to $\left[\mathrm{CpMCl}_{2}\right]_{2}$-type compounds, is related to the stronger metalmetal interactions established by the latter metal. ${ }^{[37]}$ For molybdenum, mononuclear $\mathrm{CpMoX}_{2} \mathrm{~L}_{2}$ complexes are the rule and the dinuclear $\mathrm{Cp}_{2} \mathrm{Mo}_{2} \mathrm{X}_{4} \mathrm{~L}_{4}$-type complex reported here is the exception, whereas for tungsten even the strong dmpe ligand stops at the dinuclear $\mathrm{Cp}_{2} \mathrm{Mo}_{2} \mathrm{X}_{4} \mathrm{~L}_{4}$-type complex.

$<$ Scheme 4>

The most interesting structural parameter of the $\mathrm{Cp}_{2} \mathrm{Mo}_{2} \mathrm{Cl}_{4}(\boldsymbol{a s}-\mathbf{o x})$ compound is the metal-metal distance [3.124(5) $\AA$ ]. It is well known that the stepwise opening of the four bridges in $\mathrm{Cp}_{2} \mathrm{Mo}_{2} \mathrm{Cl}_{4}$ is accompanied by a weakening of the metal-metal interaction. Indeed 
this distance is shorter in the quadruply-bridged $\mathrm{Cp}^{\prime}{ }_{2} \mathrm{Mo}_{2}(\mu-\mathrm{Cl})_{4}[2.607(1) \AA]^{[38]}$ and $\mathrm{Cp}_{2} \mathrm{Mo}_{2}(\mu-\mathrm{SMe})_{4}[2.603(2) \AA],{ }^{[39]}$ intermediate in triply bridged $\left[\mathrm{Cp}_{2} \mathrm{Mo}_{2}(\mu-\mathrm{SMe})_{3}(\mathrm{CO})_{2}\right]^{+}$ $[2.785(2) \AA]^{[40]}$ and $\left[\mathrm{Cp}_{2} \mathrm{Mo}_{2}(\mu-\mathrm{SMe})_{2}(\mu-\mathrm{SH})(\mathrm{CO})_{2}\right]^{+}[2.772(2) \AA],{ }^{[41]}$ and longer in doubly bridged $\left[\mathrm{Cp}_{2} \mathrm{Mo}_{2}(\mu-\mathrm{StBu})_{2}(\mathrm{CO})_{4}\right]^{2+}[3.008(2) \AA],{ }^{[35]}\left[\mathrm{Cp}_{2} \mathrm{Mo}_{2}(\mu-\mathrm{SMe})_{2}(\mathrm{MeCN})_{4}\right]^{2+}[3.0000(6)$ $\AA]^{[42]}$ and $\left[\mathrm{Cp}_{2} \mathrm{Mo}_{2}(\mu-\mathrm{SPh})_{2}(\mathrm{CO})_{3}(\mathrm{MeCN})\right]^{+}[3.006(3) \AA] .{ }^{[43]}$ For the related $\mathrm{W}$ complex $\mathrm{Cp}_{2}{ }_{2} \mathrm{~W}_{2} \mathrm{Cl}_{4}(\mathrm{dmpe})$, the $\mathrm{W}-\mathrm{W}$ distance is $3.196(1) \AA{ }^{[36]}$ Another interesting feature is the variation of the Mo-Cl bond distance and the bond distances related to the $\mathrm{Mo}(\mathrm{dad})$ moiety, in comparison with the structure of $\mathrm{CpMoCl}_{2}\left[\left(\mathrm{C}_{6} \mathrm{H}_{3} i \mathrm{Pr}_{2}-2,6\right)_{2} \mathrm{dad}\right] .{ }^{[44]}$ The terminal $\mathrm{Mo}(2)-\mathrm{Cl}$ distances [average 2.48(2) $\AA$ ] are much longer than in the mononuclear complex [average 2.40(2) $\AA$ ], but correspond closely to those of other $\mathrm{CpMoCl}_{2} \mathrm{~L}_{2}$ compounds (e.g. average of 2.471(3) $\AA^{[45]}$ for $\mathrm{L}=\mathrm{PMe}_{3}$ ). The bridging Mo-Cl bonds are also longer [average 2.45(1) $\AA$ ]. On the other hand, the $\mathrm{N}-\mathrm{C}$ and $\mathrm{C}-\mathrm{C}$ distances of the bis(oxazoline) ligand are respectively shorter [average 1.284(7) $\AA$ ] and longer [1.446(6) $\AA$ ] than the same distances in the mononuclear complex [1.352(2) $\AA$ and 1.363(2) $\AA$, respectively]. All these differences point to a more appropriate description of the coordination as involving a dative interaction between the neutral bis(oxazoline) ligand and a Mo ${ }^{\mathrm{III}}$ center, whereas the mononuclear complex has a stronger contribution from a resonance form formally viewed as containing a covalently bonded (enediamido) $\mathrm{Mo}^{\mathrm{V}}$ moiety. Other complexes where diazadiene ligands bind prevalently through a dative interaction also display shorter $\mathrm{C}-\mathrm{N}$ and longer $\mathrm{C}-\mathrm{C}$ distances, e.g. average 1.269(4) $\AA$ and 1.476(4) $\AA$, respectively, in $\mathrm{MoO}_{2} \mathrm{Cl}_{2}\left(t \mathrm{Bu}_{2} \mathrm{dad}\right) .{ }^{[46]}$ The Mo atom is close to the least squares plane defined by the N-C-C-N chelate (distance $=0.20(1) \AA$ ).

\section{(b) Controlled radical polymerizations}


Complexes $\mathrm{CpMoCl}_{2}(\mathbf{R} * 2 \mathbf{d a d})$ and $\mathrm{Cp}_{2} \mathrm{Mo}_{2} \mathrm{Cl}_{4}(\boldsymbol{a s}-\mathbf{o x})$ have been tested as catalysts for the ATRP of styrene. The polymerization with the former complex was carried out under the typical conditions already applied for related $\mathrm{CpMoCl}_{2}\left(\mathrm{R}_{2} \mathrm{dad}\right)$ compounds, using the iodo derivative $\mathrm{CH}_{3} \mathrm{CH}(\mathrm{I}) \mathrm{COOEt}$ (IEA) as an initiator, and one equivalent of $\mathrm{Al}(\mathrm{O} i \mathrm{Pr})_{3}$ as a cocatalyst. $^{[5]}$ A rationalization for the mode of action of this co-catalyst has been reported separately. ${ }^{[2,47]}$ The results are shown in Figure 2. The polymerization with complex $\mathrm{Cp}_{2} \mathrm{Mo}_{2} \mathrm{Cl}_{4}$ (as-ox) was carried out with 1-bromoethylbenzene (BEB) as an initiator, and without the $\mathrm{Al}(\mathrm{O} i \mathrm{Pr})_{3}$ co-catalyst. Both the IEA and BEB initiators have been shown to lead to a controlled polymerization of styrene with other Mo-based catalysts. ${ }^{[5]}$ For both systems, we observe that the molecular weights increase linearly with conversion and that the polydispersity indexes (PDI) are relatively low (down to ca. 1.3). Note that the initiator efficiency factor is low in each case $(f=0.6)$. The same phenomenon occurs for the previously described $\mathrm{CpMoCl}_{2}\left(\mathrm{R}_{2}\right.$ dad $)$ catalysts. ${ }^{[5]}$ In addition, the monomer consumption follows in each case first order kinetics, see Figure 3. This is as expected for a controlled process. The rate of monomer consumption is quite a bit slower with complex $\mathrm{Cp}_{2} \mathrm{Mo}_{2} \mathrm{Cl}_{4}$ (asox) $\left[k_{\mathrm{app}}=5.4 \cdot 10^{-5} \mathrm{~min}^{-1}\right]$ than with the mononuclear complex $\mathrm{CpMoCl}_{2}\left(\mathbf{R}_{2}\right.$ dad $)\left[k_{\mathrm{app}}=\right.$ 4.2 $\left.10^{-4} \mathrm{~min}^{-1}\right]$. The latter is close to that measure previously by using complex $\mathrm{CpMoCl}_{2}\left(i \mathrm{Pr}_{2} \mathrm{dad}\right)$ under the same conditions $\left(k_{\mathrm{app}}=3.0 \cdot 10^{-4} \mathrm{~min}^{-1}\right)$. The lower activity of the dinuclear complex could at least in part be attributed to the absence of the $\mathrm{Al}(\mathrm{O} i \mathrm{Pr})_{3}$ cocatalyst, since an accelerating factor of ca. 17 has been observed in the presence of one equivalent of this compound for the related $\mathrm{CpMoCl}_{2}\left(i \mathrm{Pr}_{2} \mathrm{dad}\right)$ catalysts. ${ }^{[5]}$

The product obtained from each procedure was analyzed by ${ }^{13} \mathrm{C} \mathrm{NMR}$, in order to see whether the ligand asymmetry had any effect on the polymer tacticity. ${ }^{[48,49]}$ However, no notable difference could be detected, relative to a polymer obtained by free radical polymerization (AIBN initiator). 
$<$ Figure 2 and Figure 3>

\section{Conclusions}

The well established family of half-sandwich $\mathrm{CpMoCl}_{2}\left(\mathrm{R}_{2} \mathrm{dad}\right)$ complexes has been extended to asymmetric members, one containing a chiral auxiliary on the nitrogen atom, $\mathbf{R}^{*}{ }_{2}$ dad $\left[\mathrm{R}^{*}=(S)-\mathrm{CH}\left(\mathrm{CH}_{3}\right) \mathrm{Ph}\right]$, the second one being based on a $\mathrm{C}_{2}$-symmetric bis(oxazoline) donor, as-ox. The latter is the first reported example of a bis(oxazoline) derivative for the half-sandwich $\mathrm{CpMo}^{\mathrm{III}}$ system. However, while the use of $\mathbf{R}_{\mathbf{2}}$ dad leads to the splitting of the dinuclear $\mathrm{Cp}_{2} \mathrm{Mo}_{2} \mathrm{Cl}_{4}$ precursor, the as-ox ligand allows for the first time the isolation of a dinuclear adduct, which may be viewed as an intermediate of the dimer splitting process. Indeed, EPR spectroscopy indicates the presence of the mononuclear species in solution. Both complexes, like the previously investigated symmetric analogues, are capable to catalyze the atom transfer radical polymerization of styrene. However, there is no indication that the asymmetric nature of the catalyst exerts any stereocontrol in the polymerization process. Among other possible factors, the probable lack of coordination of the monomer to the asymmetric catalyst may contribute to this result. In fact, the 17-electron nature of the half-sandwich $\mathrm{Mo}^{\mathrm{III}}$ center does not leave available positions for coordination of a 2-electron donor. It does, however, allow the increase of both the number of valence electrons and the coordination number by one unit, as required by the atom transfer process.

Acknowedgements. We are grateful to the CNRS for financial help. This project started with funding by a national CNRS program entitles "Catalyse et catalyseurs pour l'industrie et 
l'environnement" (1997-98). The European COST D17 programme (working group

D17/0007/00) is also acknowledged for additional financial help.

\section{References}

[1] K. Matyjaszewski, J. H. Xia, Chem. Rev. 2001, 101, 2921.

[2] M. Kamigaito, T. Ando, M. Sawamoto, Chem. Rev. 2001, 101, 3689.

[3] Y. Kabachii, S. Kochev, L. Bronstein, I. Blagodatskikh, P. Valetsky, Polym. Bull. 2003, 50, 271.

[4] E. Le Grognec, J. Claverie, R. Poli, J. Am. Chem. Soc. 2001, 123, 9513.

[5] F. Stoffelbach, D. M. Haddleton, R. Poli, Eur. Polym. J. 2003, 39, 2099.

[6] Y. Kotani, M. Kamigaito, M. Sawamoto, Macromolecules 1999, 32, 2420.

[7] Y. Kotani, M. Kamigaito, M. Sawamoto, Macromolecules 1999, 32, 6877.

[8] V. C. Gibson, R. K. O'Reilly, W. Reed, D. F. Wass, A. J. P. White, D. J. Williams, Chem. Commun. 2002, 1850.

[9] T. Ando, M. Kamigaito, M. Sawamoto, Macromolecules 2000, 33, 6732.

[10] H. Uegaki, Y. Kotani, M. Kamigaito, M. Sawamoto, Macromolecules 1997, 30, 2249.

[11] H. Uegaki, M. Kamigaito, M. Sawamoto, J. Polym. Sci., Polym. Chem. 1999, 37, 3003.

[12] J. Guo, Z. Han, P. Wu, J. Mol. Catal. A 2000, 159, 77.

[13] D. M. Haddleton, A. J. Clark, M. C. Crossman, D. J. Duncalf, A. M. Heming, S. R. Morsley, A. J. Shooter, Chem. Comm. 1997, 1173.

[14] D. M. Haddleton, S. Perrier, S. A. F. Bon, Macromolecules 2000, 33, 8246.

[15] X. S. Wang, S. P. Armes, Macromolecules 2000, 33, 6640.

[16] S. Harrisson, J. Rourke, D. Haddleton, Chem. Commun. 2002, 1470.

[17] D. Singleton, D. Nowlan, N. Jahed, K. Matyjaszewski, Macromolecules 2003, 36, 8609.

[18] W. A. Braunecker, T. Pintauer, N. V. Tsarevsky, G. Kickelbick, K. Matyjaszewski, J. Organomet. Chem. 2005, 690, 916.

[19] N. A. Porter, B. Giese, D. P. Curran, Acc. Chem. Res. 1991, 24, 296.

[20] Y. Isobe, Y. Suito, S. Habaue, Y. Okamoto, J. Polym. Sci., Polym. Chem. 2003, 41, 1027.

[21] J. Lutz, D. Neugebauer, K. Matyjaszewski, J. Am. Chem. Soc. 2003, 125, 6986.

[22] F. Stoffelbach, R. Poli, Chem. Commun. 2004, 2666

[23] R. Poli, F. Stoffelbach, S. Maria, J. Mata, Chem. Eur. J. 2005, 11, 2537.

[24] H. Brunner, W. Zettelmeier, Handbook of Enantioselective Catalysis, vol. II, VCH, 1993.

[25] F. Abugideiri, R. Poli, in Synthetic Methods of Organometallic and Inorganic Chemistry (Herrmann/Brauer), Vol. 8 (Ed.: W. A. Herrmann), Georg Thieme Verlag, Stuttgart, 1997, pp. 102.

[26] D. P. Curran, E. Bosch, J. Kaplan, M. Newcomb, J. Org. Chem. 1989, 54, 1826.

[27] I. Butula, G. Karlovic, Justus Liebigs Annalen der Chemie 1976, 1455.

[28] P. T. Beurskens, G. Beurskens, R. d. Gelder, S. Garcia-Granda, R. Israel, R. O. Gould, J. M. M. Smits, The DIRDIF-99 program system, Crystallography Laboratory, University of Nijmegen, The Netherlands, 1999.

[29] G. M. Sheldrick, SHELXL97. Program for Crystal Structure refinement, University of Göttingen, Göttingen, Germany, 1997. 
[30] L. J. Farrugia, J. Appl. Crystallogr. 1999, 32, 837.

[31] J. M. Kliegman, R. K. Barnes, J. Org. Chem. 1970, 35, 3140.

[32] J. M. Kliegman, R. K. Barnes, Tetrahedron 1970, 26, 2555.

[33] H. tom Dieck, I. W. Renk, Chem. Ber. 1971, 104, 92.

[34] L. Jafarpour, E. D. Stevens, S. P. Nolan, J. Organomet. Chem. 2000, 606, 49.

[35] J. Courtot-Coupez, M. Guéguen, J. E. Guerchais, F. Y. Pétillon, J. Talarmin, R. Mercier, J. Organometal. Chem. 1986, 312, 81.

[36] M. L. H. Green, P. Mountford, J. Chem. Soc., Chem. Commun. 1989, 732.

[37] M. L. H. Green, P. Mountford, Chem. Soc. Rev. 1992, 29.

[38] P. D. Grebenik, M. L. H. Green, A. Izquierdo, V. S. B. Mtetwa, K. Prout, J. Chem. Soc., Dalton Trans. 1987, 9.

[39] N. G. Connelly, L. F. Dahl, J. Am. Chem. Soc. 1970, 92, 7470.

[40] M. B. Gomes de Lima, J. E. Guerchais, R. Mercier, F. Y. Pétillon, Organometallics 1986, $5,1952$.

[41] P. Schollhammer, F. Y. Pétillon, R. Pichon, S. Poder-Guillou, J. Talarmin, K. W. Muir, L. Manojlovic-Muir, Organometallics 1995, 14, 2277.

[42] P. Schollhammer, F. Y. Pétillon, J. Talarmin, K. W. Muir, Inorg. Chim. Acta 1999, 284, 107.

[43] M. El Khalifa, M. Guéguen, R. Mercier, F. Y. Pétillon, J.-Y. Saillard, J. Talarmin, Organometallics 1989, 8, 140.

[44] F. Stoffelbach, R. Poli, P. Richard, J. Organometal. Chem. 2002, 663, 269.

[45] S. T. Krueger, R. Poli, A. L. Rheingold, D. L. Staley, Inorg. Chem. 1989, 28, 4599.

[46] K. Dreisch, C. Andersson, C. Stalhandske, Polyhedron 1993, 12, 303.

[47] R. Poli, F. Stoffelbach, S. Maria, J. Mata, Chem. Eur. J. in press.

[48] Y. Inoue, A. Nishioka, R. Chujo, Makromol. Chem. 1972, 156, 207.

[49] D. Baudry-Barbier, E. Camus, A. Dormond, M. Visseaux, Appl. Organometal. Chem. 1999, 13, 813. 
Table 1. Crystal data and structure refinement for compound $\mathrm{Cp}_{2} \mathrm{Mo}_{2} \mathrm{Cl}_{4}($ as $-\mathbf{o x})$.

Formula

$\mathrm{M}$

$\mathrm{T} ; \mathrm{K}$

Crystal system

Space group

$\mathrm{a} ; \AA$

b; $\AA$

c; $\AA$

$\mathrm{V} ; \AA^{3}$

$\mathrm{Z}$

$\mathrm{F}(000)$

$\mathrm{D}_{\text {calc }} ; \mathrm{g} / \mathrm{cm}^{3}$

diffractometer

scan type

$\lambda ; \AA$

$\mu ; \mathrm{mm}^{-1}$

Crystal size; $\mathrm{mm}^{3}$

$\sin (\theta) / \lambda \max ; \AA^{-1}$

Index ranges

$\mathrm{RC}=$ Refl. Collected

IRC $=$ independent RC

IRCGT $=$ IRC and $[\mathrm{I}>2 \sigma(\mathrm{I})]$

Refinement method

Data / restraints / parameters

Absolute structure parameter

$\mathrm{R}$ for IRCGT

$\mathrm{R}$ for IRC

Goodness-of-fit ${ }^{\mathrm{c}}$

Largest diff. peak and hole; e. $\AA^{-3}$
$\mathrm{C}_{20} \mathrm{H}_{26} \mathrm{~N}_{2} \mathrm{O}_{2} \mathrm{Cl}_{4} \mathrm{Mo}_{2}$

660.11

$110(2)$

Orthorhombic

$\mathrm{P} 2{ }_{1} 2{ }_{1}{ }_{1}$

12.4051(6)

$13.6827(7)$

14.0961(8)

2392.6(2)

4

1312

1.833

Enraf-Nonius KappaCCD

mixture of $\phi$ rotations and $\omega$ scans

0.71073

1.515

$0.23 \times 0.14 \times 0.14$

0.65

h: $-16 ; 12$

$\mathrm{k}:-11 ; 17$

l: $-17 ; 18$

9714

$5226[\mathrm{R}(\mathrm{int})=0.0499]$

4094

Full-matrix least-squares on $\mathrm{F}^{\wedge} 2$

$5226 / 0 / 272$

$0.00(6)$

$\mathrm{R} 1^{\mathrm{a}}=0.0415, \mathrm{wR} 2^{\mathrm{b}}=0.0683$

$\mathrm{R} 1^{\mathrm{a}}=0.0643, \mathrm{wR} 2^{\mathrm{b}}=0.0756$

0.993

0.737 and -0.965

${ }^{\mathrm{a}} \mathrm{R} 1=\Sigma\left(|| \mathrm{F}_{\mathrm{o}}|-| \mathrm{F}_{\mathrm{c}}||\right) / \Sigma\left|\mathrm{F}_{\mathrm{o}}\right|$.

$\mathrm{b} \quad \mathrm{wR} 2=\left[\Sigma \mathrm{w}\left(\mathrm{F}_{\mathrm{o}}^{2}-\mathrm{F}_{\mathrm{c}}\right)^{2} / \Sigma\left[\mathrm{w}\left(\mathrm{F}_{\mathrm{o}}\right)^{2}\right]^{1 / 2} \quad\right.$ where $\quad \mathrm{w}=1 /\left[\sigma^{2}\left(\mathrm{Fo}^{2}\right)+(0.0184 * \mathrm{P})^{2}\right] \quad$ where $\mathrm{P}=\left(\mathrm{Max}\left(\mathrm{Fo}^{2}, 0\right)+2 * \mathrm{Fc}^{2}\right) / 3$

${ }^{\mathrm{c}}$ Goodness of fit $=\left[\sum \mathrm{w}\left(\mathrm{F}_{\mathrm{o}}{ }^{2}-\mathrm{F}_{\mathrm{c}}{ }^{2}\right)^{2} /\left(\mathrm{N}_{\mathrm{o}}-\mathrm{N}_{\mathrm{v}}\right)\right]^{1 / 2}$. 
Table 2. Selected bond lengths $[\AA]$ and angles $\left[{ }^{\circ}\right]$ for compound $\mathrm{Cp}_{2} \mathrm{Mo}_{2} \mathrm{Cl}_{4}$ (as-dioxazoline).

Distances $(\AA)$

\begin{tabular}{llll}
\hline $\mathrm{Mo}(1)-\mathrm{CNT}(1)$ & $1.949(6)$ & $\mathrm{Mo}(2)-\mathrm{CNT}(2)$ & $1.954(6)$ \\
$\mathrm{Mo}(1)-\mathrm{Cl}(1)$ & $2.4609(15)$ & $\mathrm{Mo}(2)-\mathrm{Cl}(1)$ & $2.4484(15)$ \\
$\mathrm{Mo}(1)-\mathrm{Cl}(2)$ & $2.4404(15)$ & $\mathrm{Mo}(2)-\mathrm{Cl}(2)$ & $2.4419(16)$ \\
$\mathrm{Mo}(1)-\mathrm{Cl}(3)$ & $2.4721(15)$ & $\mathrm{Mo}(2)-\mathrm{N}(1)$ & $2.148(5)$ \\
$\mathrm{Mo}(1)-\mathrm{Cl}(4)$ & $2.4774(16)$ & $\mathrm{Mo}(2)-\mathrm{N}(2)$ & $2.136(5)$ \\
$\mathrm{Mo}(1)-\mathrm{Mo}(2)$ & $3.1243(5)$ & $\mathrm{C}(8)-\mathrm{C}(9)$ & $1.446(6)$ \\
$\mathrm{N}(1)-\mathrm{C}(8)$ & $1.288(7)$ & $\mathrm{N}(2)-\mathrm{C}(9)$ & $1.280(7)$ \\
\hline
\end{tabular}

Angles $\left({ }^{\circ}\right)$

\begin{tabular}{lcll}
\hline $\mathrm{CNT}(1)-\mathrm{Mo}(1)-\mathrm{Cl}(1)$ & $111.5(2)$ & $\mathrm{CNT}(2)-\mathrm{Mo}(2)-\mathrm{Cl}(1)$ & $113.9(2)$ \\
$\mathrm{CNT}(1)-\mathrm{Mo}(1)-\mathrm{Cl}(2)$ & $110.4(2)$ & $\mathrm{CNT}(2)-\mathrm{Mo}(2)-\mathrm{Cl}(2)$ & $112.9(2)$ \\
$\mathrm{CNT}(1)-\mathrm{Mo}(1)-\mathrm{Cl}(3)$ & $107.8(2)$ & $\mathrm{CNT}(2)-\mathrm{Mo}(2)-\mathrm{N}(1)$ & $110.4(2)$ \\
$\mathrm{CNT}(1)-\mathrm{Mo}(1)-\mathrm{Cl}(4)$ & $108.2(2)$ & $\mathrm{CNT}(2)-\mathrm{Mo}(2)-\mathrm{N}(2)$ & $113.4(2)$ \\
$\mathrm{Cl}(1)-\mathrm{Mo}(1)-\mathrm{Cl}(2)$ & $79.57(4)$ & $\mathrm{Cl}(1)-\mathrm{Mo}(2)-\mathrm{Cl}(2)$ & $79.79(4)$ \\
$\mathrm{Cl}(2)-\mathrm{Mo}(1)-\mathrm{Cl}(3)$ & $141.74(5)$ & $\mathrm{N}(1)-\mathrm{Mo}(2)-\mathrm{N}(2)$ & $74.45(13)$ \\
$\mathrm{Cl}(1)-\mathrm{Mo}(1)-\mathrm{Cl}(3)$ & $85.18(5)$ & $\mathrm{N}(1)-\mathrm{Mo}(2)-\mathrm{Cl}(1)$ & $135.43(12)$ \\
$\mathrm{Cl}(2)-\mathrm{Mo}(1)-\mathrm{Cl}(4)$ & $86.12(5)$ & $\mathrm{N}(1)-\mathrm{Mo}(2)-\mathrm{Cl}(2)$ & $87.35(12)$ \\
$\mathrm{Cl}(1)-\mathrm{Mo}(1)-\mathrm{Cl}(4)$ & $140.29(5)$ & $\mathrm{N}(2)-\mathrm{Mo}(2)-\mathrm{Cl}(1)$ & $84.15(13)$ \\
$\mathrm{Cl}(3)-\mathrm{Mo}(1)-\mathrm{Cl}(4)$ & $83.63(4)$ & $\mathrm{N}(2)-\mathrm{Mo}(2)-\mathrm{Cl}(2)$ & $133.63(12)$ \\
$\mathrm{Cl}(3)-\mathrm{Mo}(1)-\mathrm{Mo}(2)$ & $93.50(4)$ & $\mathrm{N}(1)-\mathrm{Mo}(2)-\mathrm{Mo}(1)$ & $88.80(12)$ \\
$\mathrm{Cl}(4)-\mathrm{Mo}(1)-\mathrm{Mo}(2)$ & $92.55(4)$ & $\mathrm{N}(2)-\mathrm{Mo}(2)-\mathrm{Mo}(1)$ & $86.47(12)$ \\
$\mathrm{Mo}(1)-\mathrm{Cl}(1)-\mathrm{Mo}(2)$ & $79.05(4)$ & $\mathrm{Mo}(1)-\mathrm{Cl}(2)-\mathrm{Mo}(2)$ & $79.57(5)$ \\
\hline
\end{tabular}

${ }^{\mathrm{a}} \mathrm{CNT}=$ cyclopentadienyl ring centroid. 


\section{Captions for Figures}

Figure 1. ORTEP view of the $\mathrm{CpMoCl}_{2}(\mu-\mathrm{Cl})_{2} \mathrm{Mo}(\boldsymbol{a s}-\mathbf{o x}) \mathrm{Cp}$ molecule. Ellipsoids are drawn at the $50 \%$ probability level. The $\mathrm{H}$ atoms are omitted for clarity.

Figure 2. $\quad \overline{\mathrm{M}_{\mathrm{n}}}$ (squares) and PDI (triangles) as a function of conversion for the PS obtained in toluene $(30 \% \mathrm{v} / \mathrm{v})$ at $90^{\circ} \mathrm{C}$ in the presence of: (a) $\mathrm{CpMoCl}_{2}(\mathbf{R} * 2 \mathbf{d a d}) / \mathrm{Al}-$ $\left(\mathrm{O}^{\mathrm{i}} \mathrm{Pr}\right)_{3} \quad(\mathrm{~S} / \mathrm{Mo} / \mathrm{IEA} / \mathrm{Al}=173 / 1 / 1 / 1) ;$ (b) $\mathrm{Cp}_{2} \mathrm{Mo}_{2} \mathrm{Cl}_{4}$ (as -ox $) \quad(\mathrm{S} / \mathrm{Mo} / \mathrm{BEB}=$ 453/1/1.6). In both graphs, the straight line corresponds to the theoretical $\overline{M_{n}}$ for $f=0.6$.

Figure 3. First order kinetics for the monomer consumption in the ATRP of styrene catalyzed by the systems $\mathrm{CpMoCl}_{2}\left(\mathrm{R}_{2}{ }_{2} \mathrm{dad}\right) / \mathrm{Al}\left(\mathrm{O}^{\mathrm{i}} \mathrm{Pr}\right)_{3} \quad$ (squares) and $\mathrm{Cp}_{2} \mathrm{Mo}_{2} \mathrm{Cl}_{4}$ (as-ox) (circles). 
Figure 1

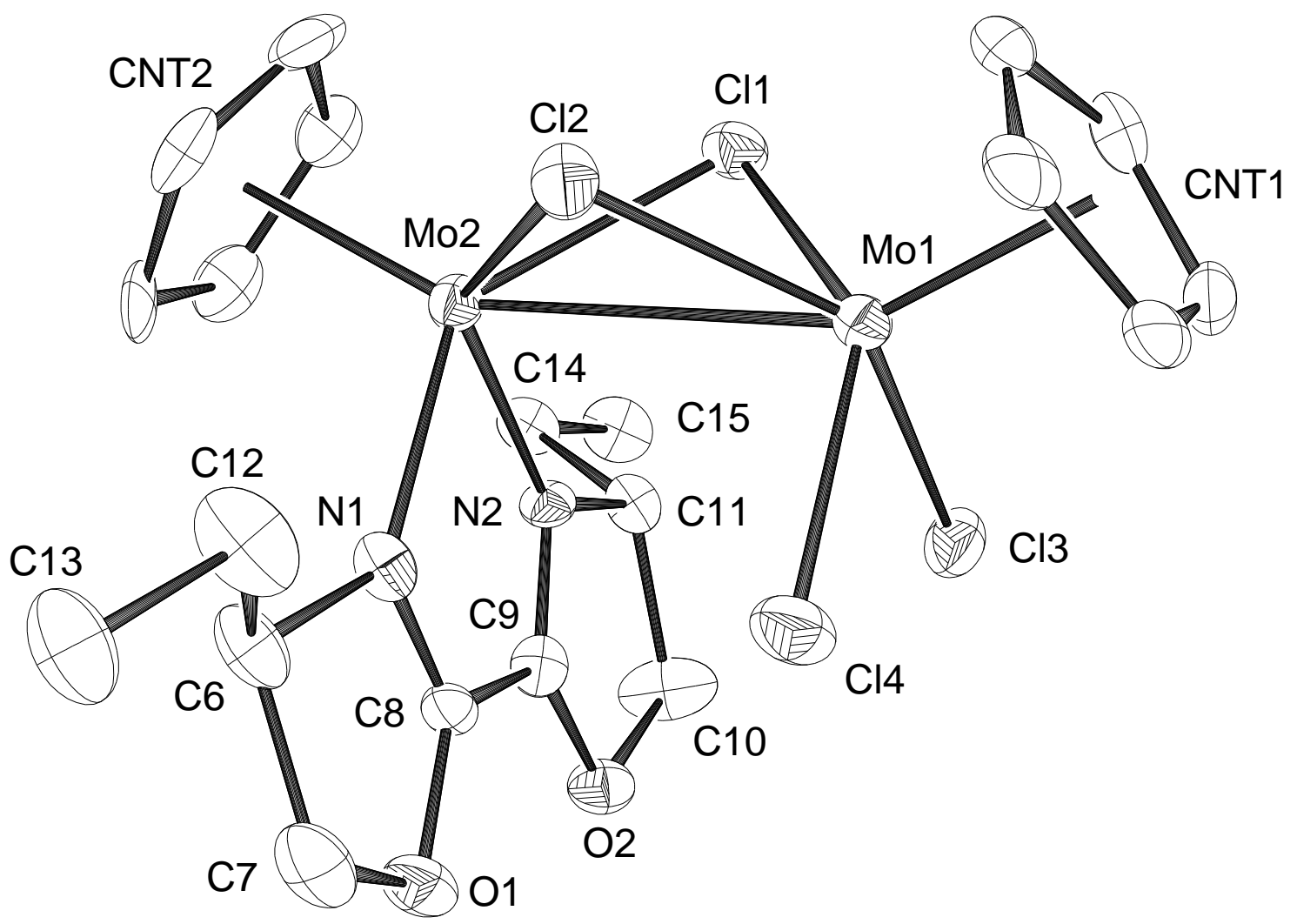


Figure 2
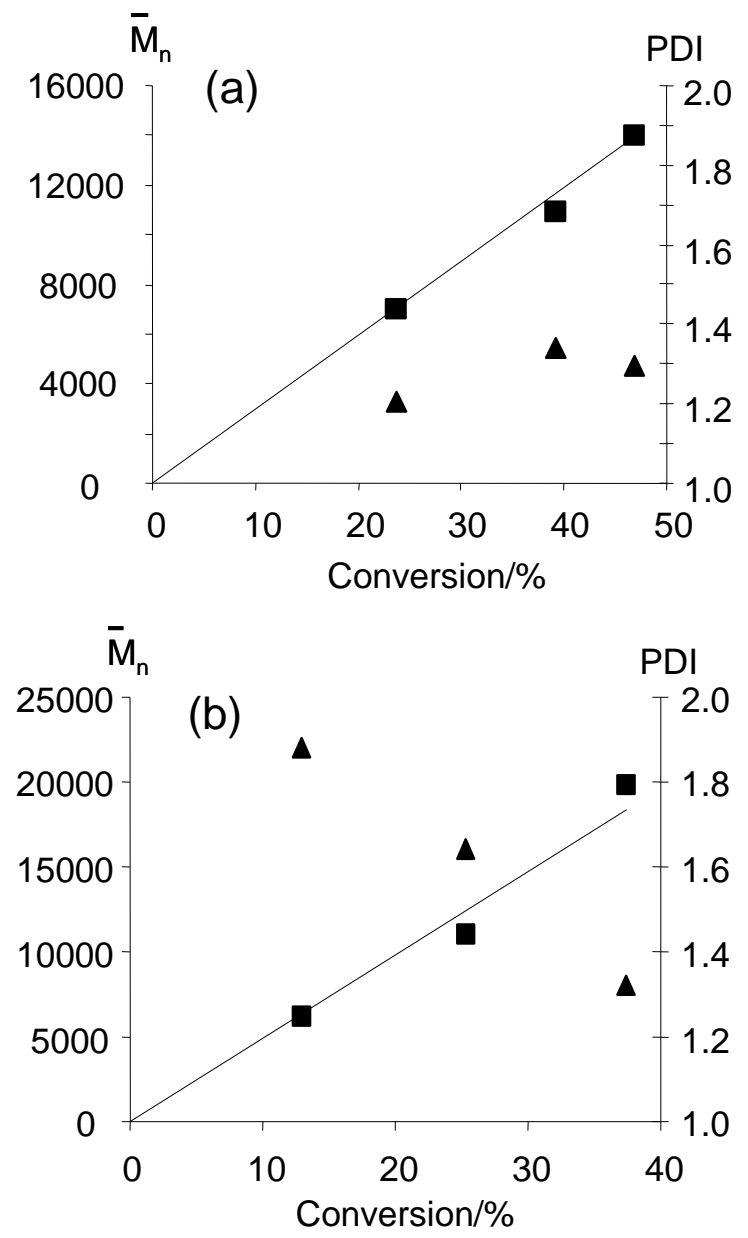

Figure 3

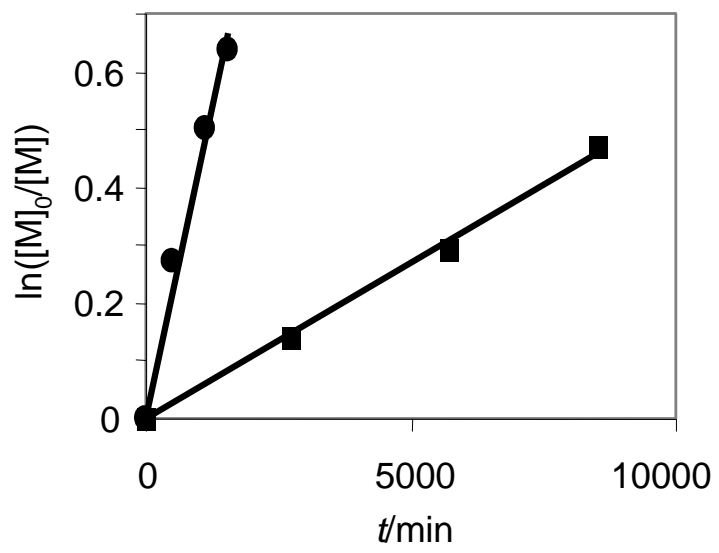


Scheme 1

$$
\mathrm{L}_{n} \mathrm{M}+\mathrm{X}-\mathrm{R} \longleftrightarrow \mathrm{L}_{\mathrm{n}} \mathrm{M}-\mathrm{X}+\mathrm{R}_{\mathrm{R}-\mathrm{R} \text { or } \mathrm{R}-\mathrm{H}+\mathrm{R}^{(-\mathrm{H})}}^{\longrightarrow}+\mathrm{m}
$$

Scheme 2

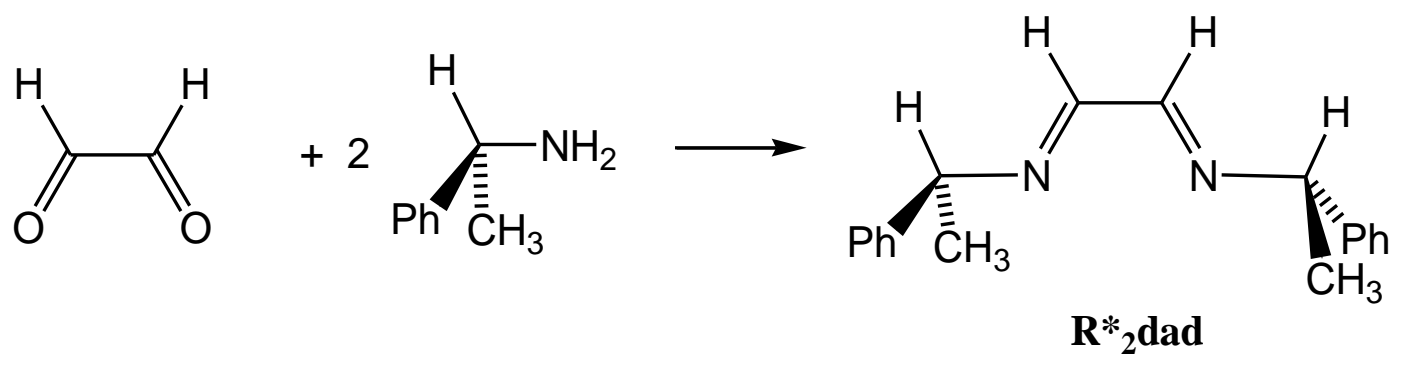

Scheme 3

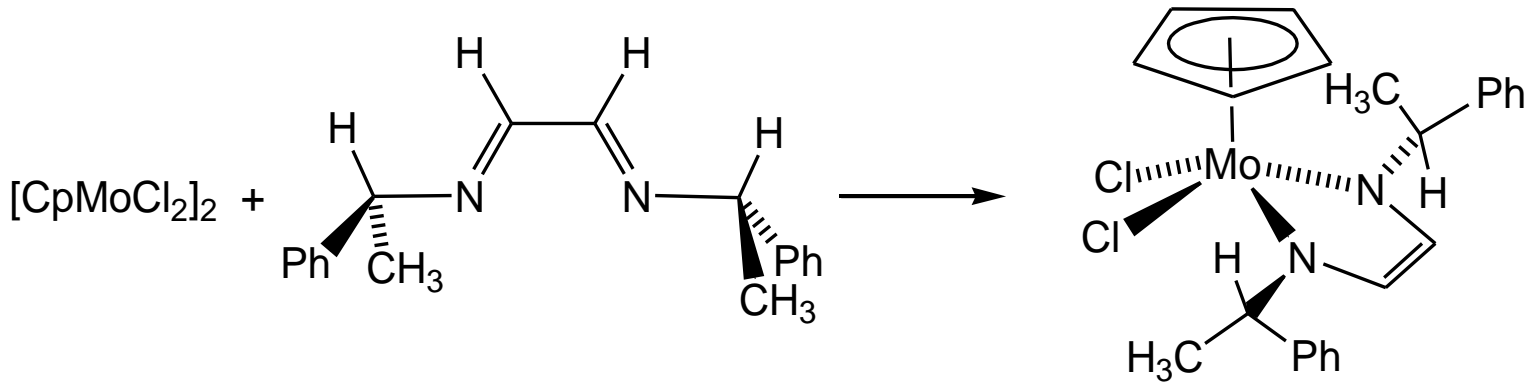

Scheme 4

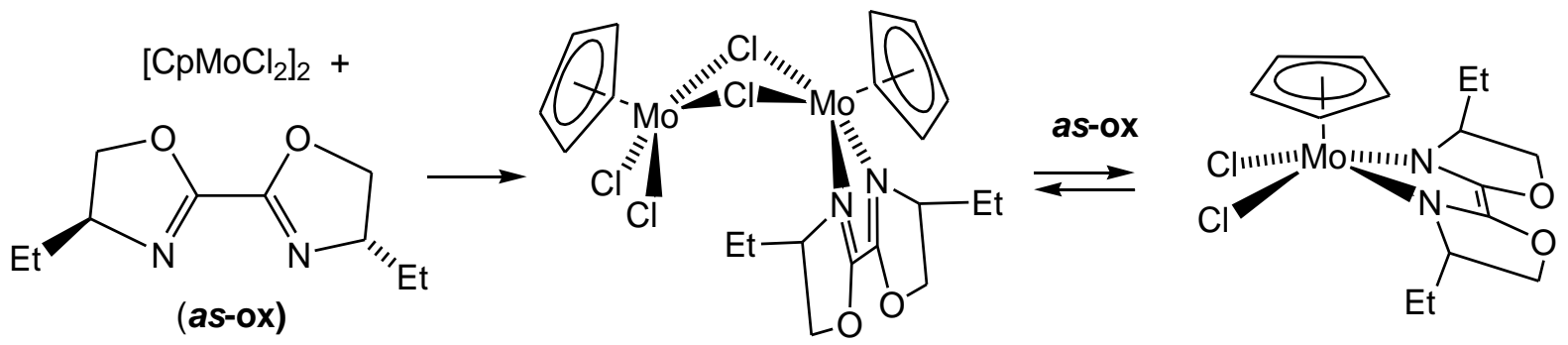

